\title{
Development of a pellet boiler with Stirling engine for m-CHP domestic application
}

\author{
Luigi Crema*, Fabrizio Alberti, Alberto Bertaso and Alessandro Bozzoli
}

\begin{abstract}
A new sustainable technology has been designed by Fondazione Bruno Kessler through its unit Renewable Energies and Environmental Technologies. This technology is realized integrating in a single system (1) a Stirling engine (mRT-1K) from a pre-engineering design of Allan J. Organ; (2) a micro-heat exchanger technology, to reduce the net transfer unit deficit on the hot side of the heat engine; (3) a customized pellet boiler, able to extract electrical and thermal power; and (4) a customized hydraulic circuit, connecting the cool side of the Stirling engine and the heat generation on the second section of the pellet boiler. The objective of this paper was to present a new technology for the micro-cogeneration of energy at a distributed level able to be integrated in domestic dwellings. Most part of the available biomass is used in buildings for the generation of thermal power for indoor heating and, in minor cases, for hot sanitary water. In the Province of Trento, 88\% of the biomass is used for this purpose. The full system is actually under integration for the test phase and not yet tested. The first tests on the single components have confirmed preliminary results on the Stirling engine with respect to the tolerances, pressurization, and proper integration of the electrical generator-driven control system. The pellet boiler has been tested separately, confirming an overall thermal efficiency of $90 \%$.
\end{abstract}

Keywords: micro-cogeneration, Stirling engine, pellet boiler, renewable energy

\section{Background}

The cogeneration of energy at a distributed level is one of the leading arguments in large part of energy policies related to renewable energy resources and systems. The actual marketable solar systems for domestic and distributed applications (photovoltaic [PV] and solar thermal) suffer notable limitations: (1) The low overall (electrical) efficiency of PV systems creates a small collected energy from the available space, sometimes restricted in the surface to a few square meters; (2) the stagnation temperatures on solar thermal collectors are actually limiting the diffusion of solar thermal systems; and (3) fixed and non-retrofittable systems may generate energy in an intermittent manner not aligned with the auto-consumption profile of domestic spaces.

On the other end, the growth of the distributed energy generation is far above all previsions, not only in new energy markets but even in highly industrialized countries. In Germany, more than $50 \%$ of the $43-\mathrm{GW}$

\footnotetext{
* Correspondence: crema@fbk.eu

Renewable Energies and Environmental Technologies Unit (REET),

Fondazione Bruno Kessler (FBK), Via alla Cascata 56/C, Povo Trento, Italy
}

installed power in 2009 is in the hands of individuals and farmers, on all sectors of solar, wind, biomass technologies [1]. At the distributed level, an increasing number of technologies are approaching the market, such as new and efficient PV or concentrated photovoltaics [2]; micro-combined heat and power [m-CHP] solutions based on solar [3], fuel cells [4], or biomass; and technologies for the efficient production of thermal energy such as ground source heat pumps, air heat pumps, and solar thermal.

The development of new cogeneration systems based on non-intermittent sources able to be coupled and eventually hybridized with other sustainable technologies is highly required. A compact micro-cogeneration system based on a pellet boiler integrated with a Stirling engine is presented, realized compatibly with the market-levelized energy cost. This paper presents, for the first time, the different stages of the development of such $\mathrm{m}$-CHP biomass technology.

Such system (see Figure 1) integrates a Stirling engine (mRT-1k) in a customized pellet boiler properly realized to generate thermal power for heating and eventual 


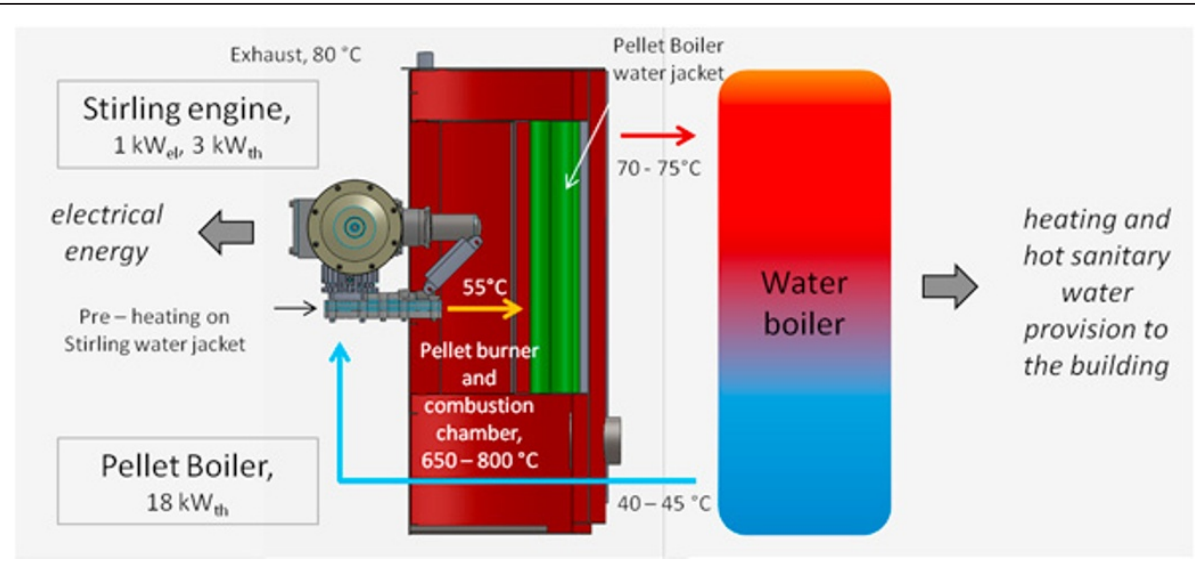

Figure 1 Technological layout for the micro-cogeneration pellet boiler.

cooling, electricity, and hot sanitary water. Four main themes have led to the development of this proposal:

- Improvements in combustion technology allow the adaptation of a retrofitted combustion chamber with the Stirling heat exchanger in a new efficient solution, optimizing the electricity generation, the heat removal from different parts of the system at different temperatures, and the overall efficiency.

- Optimized Stirling engines and new compact heat exchanger technology can reduce the costs and improve the performance of small heat engines, so they can operate with higher proportions of Carnot efficiency on the working temperatures $\left(\sim 600^{\circ} \mathrm{C}\right)$ from the combustion burner.

- The high cost and low power efficiency of gasfuelled m-CHP systems, combined with increases in natural gas prices, both absolute and relative to electricity prices, can undermine the financial viability of gas-fuelled m-CHP. There is an urgent need for alternative m-CHP systems, of which solar or biomass $\mathrm{m}$-CHP, whether separately or as a hybrid, is an option with high potential.

The system may work in two different operative modes:

1. Generating the electrical power only when thermal energy is required by the building

2. Generating the electrical power dissipating the extra thermal energy not required by the building

The first will be used in most parts of the applications where a grid connection is available, and the second will regard remote locations (mountain cottages) where the grid connection is not present. An electrical energy storage will be required to match energy generation with end-user demand of energy. In both cases, the pellet boiler will be provided with a volumetric control of the pellet in order to make the burner work at a low power $\left(>5 \mathrm{~kW}_{\mathrm{th}}\right)$.

\section{Materials and methods}

\section{Introduction to economical aspects}

The biomass combustion systems (biomass boilers and stoves) are one of the most diffused and cost-effective heating systems in the Alpine region. The overall efficiency obtained by the best and state-of-the-art technologies is comparable to those on natural gas or fossil fuel boilers, with values above $80 \%$. The $\mathrm{m}$-CHP generation from a pellet or wood burner is a potential added value to the base technology.

A market analysis reveals that Italy is the first European country in the specific market sector of the pellet stoves, accounting for 800,000 domestic systems installed at 2008 and 380,000 units produced in 2006. It adds a growth of $300 \%$ in the last 5 years (2003-2008) in pellet consumption and use. To have a comparison data, in Europe, there have been 4.4 Mt produced in 2006 with respect to $8.4 \mathrm{Mt}$ in 2010 [5]. In the European energy market, biomass has a share of $51 \%$ with respect to the energy produced by renewable sources, of which $85 \%$ comes from domestic plants and about 15\% from industrial plants (multistage combustion, gasification, pyrolysis processes). In addition, the direct production of thermal energy from renewable sources, about $97 \%$, comes from biomass combustion [6]. In addition, 97\% of all direct thermal energy from renewable sources comes from biomass combustion.

A recent report from Frost and Sullivan [7] showed that biomass can provide a strong support to renewable energies in the European context. This source provides currently two thirds of the specific sector and has a strong growing margin since the raw material produced 
in the EU 25 territory is increasing. The same report underlines the biomass context, which is wrongly considered an energy resource of the past, that financing support for technological development can provide solutions for an advanced system, reduction of costs (the conversion ratio $€ / \mathrm{kW}$ is one of the more advantageous in the market, with costs lower than $2,000 € / \mathrm{kWe}$ ), environmental sustainability, and lower levels of impact.

The present project aims to realize a system which is capable of covering a part of the demand for electrical energy and the demand for thermal energy for heating and hot sanitary water purposes.

Following are some considerations on domestic system for cogeneration:

- There is a good match between production and demand of electrical energy since a pellet stove is mainly used during the part of the day which also has an electrical demand. For this reason, most of the electrical energy is consumed locally.

-Modularity of the generation system: The system can support different demands of electrical and thermal power. The electrical conversion ratio and the thermal output can be regulated by changing the load in the combustion chamber.

- The external combustion engine provides a silent, clean, and reliable system with limited cost for management and maintenance.

-With an averaged electrical efficiency from a full load to a partial load of about $10 \%$, the electrical potential production is $3 \mathrm{TWh}_{\mathrm{e}} /$ year for the $8,400,000$ tons of pellets produced yearly in Europe. Since the wood production is at least one order of magnitude higher, the whole potential electrical production is $35 \mathrm{TWh} /$ year, which is roughly one tenth of the electrical production in EU from nuclear plant.

\section{The pellet boiler m-CHP system}

The pellet cogeneration boiler is based on the integration between a Stirling engine and a biomass pellet boiler. The subcomponents of the specific technology are under integration. They include a Stirling engine, the $\underline{m R T-1 k}$, pre-engineered by Allan J. Organ [8].

The overall system is designed as illustrated in Figure 1. The Stirling engine is integrated directly inside the combustion chamber. Its heat exchanger is immediately above the burner. The Stirling engine can start operating and generating electrical and thermal power after a transient time to keep the engine at proper working conditions (hot and cold temperatures, energy flow through the heat exchanger). A drive control electronic system activates the Stirling engine controlling the generator and making it working as a motor.

A spiral screw, electronically controlled, advances the pellet. The burner is designed to provide stoichiometric primary air to realize a flame of $18 \mathrm{~kW}_{\mathrm{th}}$. The pellet boiler is mainly composed of (1) a burning chamber connected to primary air which is blown inside using a forced flow system; (2) an internal water circuit to remove thermal power after the Stirling engine and maintain the exhaust temperature in the range of $80^{\circ} \mathrm{C}$; and (3) an external water boiler to store thermal energy for the heating of the indoor environment and the production of hot sanitary water. The hydraulic system comes from the boiler; the water is pumped inside the cold end of the Stirling engine to cool and maintain a temperature of about $45-50^{\circ} \mathrm{C}$. It goes to the boiler heat remover and goes back to the water boiler at a temperature of about $75^{\circ} \mathrm{C}$. The mass flow of the pellet and the water will be calibrated as a function of the energy balance able to maintain the system in a steady-state thermal condition. The electrical power is derived by the engine adapting to the specific condition of the grid connection and acting through a load management system.

\section{Measurement system}

The integrated technology will be provided with a centralized measurement and control system (see Figure 2 ). It will be directly connected to the different subcomponents. The controller monitors temperatures in and out from the boiler water jacket, inside the Stirling engine, in the expander cylinder, in the compression cylinder, at the input and at the output of the water circuit, at the exhaust of the boiler, the volume flow on the water circuit passing though the Stirling, and inside the pellet boiler. Furthermore, the pressure sensors, both for dynamic and absolute values, are positioned inside the Stirling engine on the heat exchanger and before the compression cylinder; the pellet mass flow sensor is located at the input of the burner. In such a way, the energy and mass balance will be monitored.

The system has been provided with thermostatic control for high temperature to activate control on the combustion chamber and stop the biomass flow to the burner in case of alarm. The system first activates the water circulation through the Stirling and the water jacket; secondly, the burner is started. The control system will monitor the transient until a threshold temperature. At that condition, the Stirling engine is activated by the generator used as a motor using the drive control as the engine speed control. The rated power will be reached. 


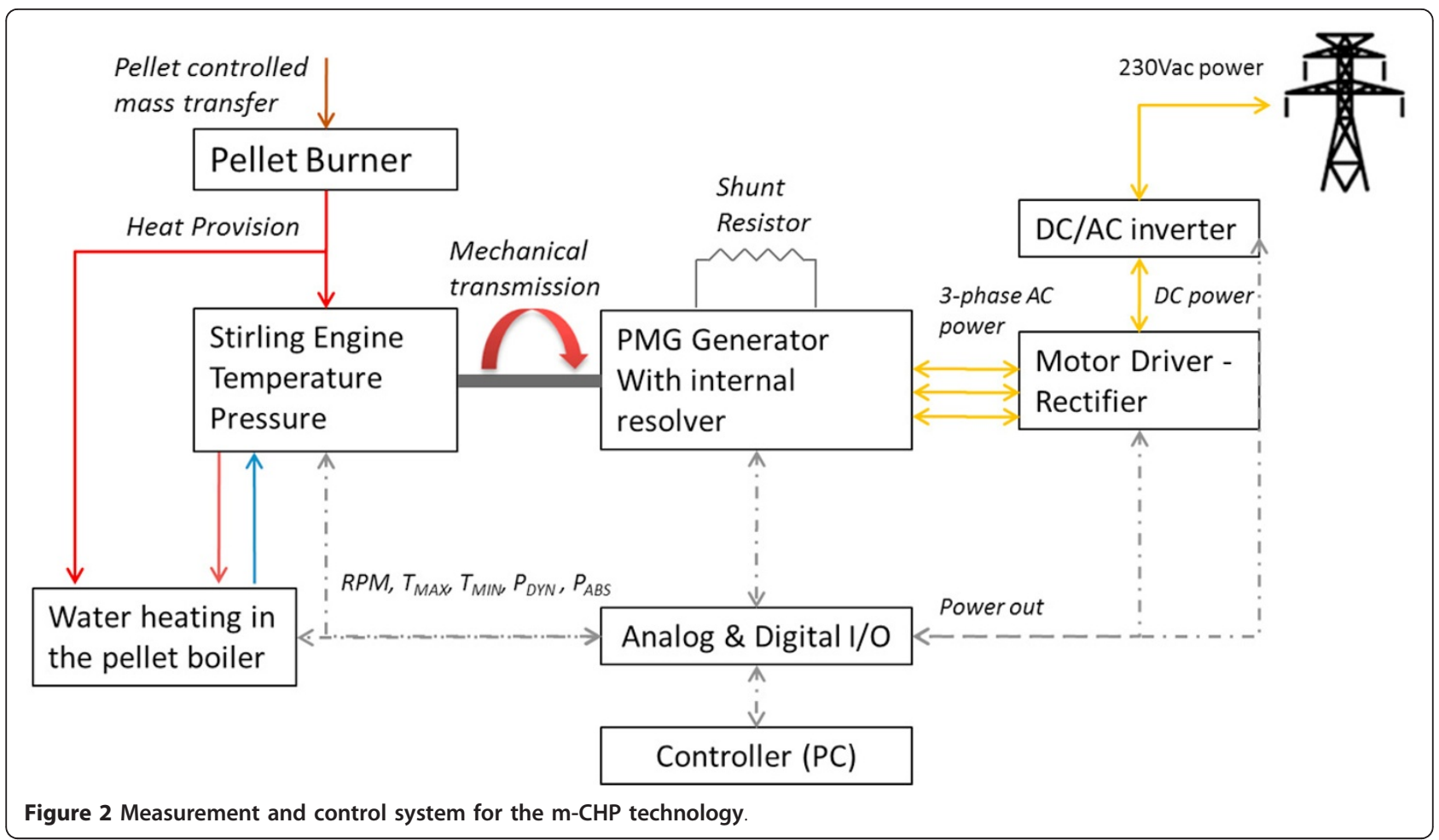

\section{Results}

\section{The cogeneration engine}

The mRT-1k engine is a $1-\mathrm{kW}$ air-charged (14-bar gauge) reciprocating Stirling engine. It is expected to be upgradeable (up to $5 \mathrm{~kW}$ and more) by (1) using higher pressure $\mathrm{He}$ as the charge gas, (2) increasing engine speed, and/or (3) scaling up in size. The initial engine, illustrated in Figure 3, is a two-cylinder, $90^{\circ}$ engine. The model of the engine gives back a rated power output of $1 \mathrm{~kW}_{\text {pick }}$ at $1,500 \mathrm{rpm}$. It is characterized by a compact design with nominal displacement, $V_{\max }-V_{\min }$ of 175 $\mathrm{cm}^{3}\left(V_{\mathrm{E}}=72 \mathrm{~cm}^{3}, V_{\mathrm{C}}=162 \mathrm{~cm}^{3}\right.$; thermodynamic volume ratio, $\kappa=2.25$ ).

It has a Beale modulus, an index for the efficiency and effectiveness of the engine, $B_{\mathrm{n}}$, given in Equation 1, which make use of symbols explained in Table 1.

$$
B_{\mathrm{n}}=\frac{W_{\mathrm{o}}}{P V F}=0.148 \text {. }
$$

This is a modest value surpassed in some established designs. But it should be possible to exceed that value, thereby improving on the target $1-\mathrm{kW}$ rating.

In Figures 3 and 4, the pre-engineering design and the advanced manufacturing stage of the engine are presented. Different critical components of the cogeneration technology have been modeled and optimized with respect to the heat transfer, fluid dynamics, and the overall efficiency extractable from the system.
Particularly, the mRT-1k has been optimized in the main components of the Stirling engine, which include:

1. Regenerator of the engine: a new technology with improved performance (under patenting process)

2. Heat exchanger: the application of the micro-heat exchanger fluid dynamics and realized through a selective laser melting [SLM] process (see Figure 5 for a pre-design of the heat exchanger)

The integration in the pellet boiler technology must respect some constraints, such as:

-Design able to realize a condition of clear surface with limited powder deposition problems

-Design able to provide an easy maintenance of the system

-High external surface exposed to the flame radiosity

-High internal surface for efficient heat transfer to the pressurized internal gas of the Stirling

The above constraints had been taken to a proposed solution of a heat exchanger based on micro-fluid dynamics, which improve the energy density transferred through the exchanger while maintaining a lower Reynolds number and, subsequently, a limited pressure drop with respect to the convective heat transfer coefficient.

The heat exchanger design has been based on the entropy generation minimization for the internal flow of 


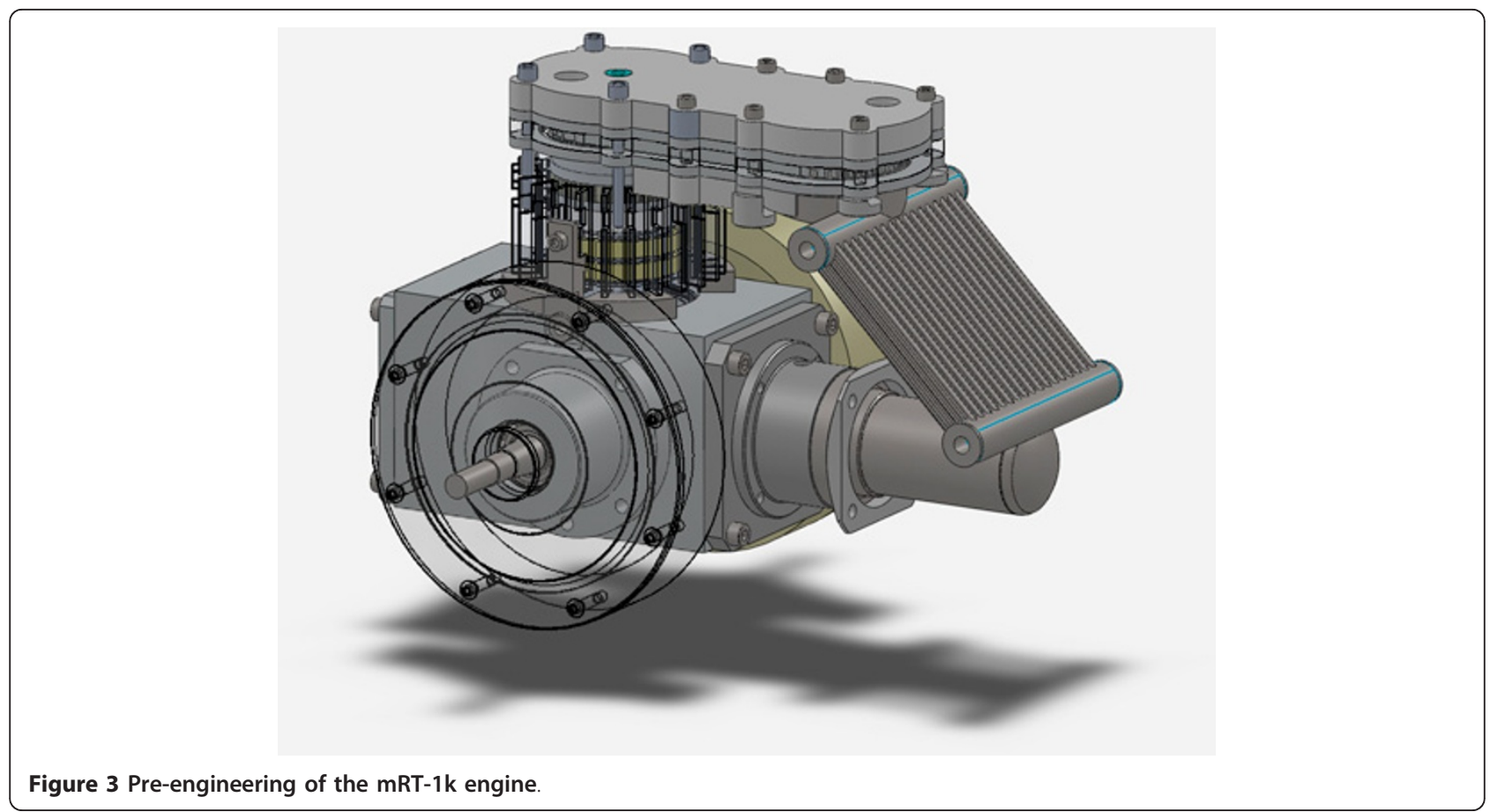

the heat exchanger, where the working fluid of the engine is located. Minimizing the entropy generations in one component is equivalent to minimizing the loss of available work. The objectives were to increase the wall

\section{Table 1 List of symbols}

\begin{tabular}{ll}
\hline$q^{\prime}$ & Heat transfer per unit length $(\mathrm{W} / \mathrm{m})$ \\
\hline $\bar{\kappa}$ & Inside diameter $(\mathrm{m})$ \\
\hline$\rho$ & Thermal conductivity $[\mathrm{W} /(\mathrm{K} \mathrm{m})]$ \\
\hline$\mu$ & Temperature $(\mathrm{K})$ \\
\hline$P$ & Density $\left(\mathrm{kg} / \mathrm{m}^{3}\right)$ \\
\hline$V_{S}$ & Dynamic viscosity $(\mathrm{Pa} \mathrm{s})$ \\
\hline$F$ & Mean average gas pressure $(\mathrm{Pa})$ \\
\hline$V$ & Swept volume - expansion space $\left(\mathrm{m}^{3}\right)$ \\
\hline$W_{0}$ & Engine cycle frequency $(\mathrm{Hz})$ \\
\hline$f$ & Nominal Displacement $\left(\mathrm{m}^{3}\right)$ \\
\hline$\dot{m}$ & Power output of the engine $(\mathrm{W})$ \\
\hline$N u$ & Friction factor \\
\hline$P r$ & Mass flow (kg/s) \\
\hline$R e$ & Nusselt number \\
\hline$N_{S}$ & Prandtl number \\
\hline$\dot{S}_{\text {gen }}^{\prime}$ & Reynolds number \\
\hline$B_{0}$ & Entropy generation number \\
\hline$V_{E}$ & Entropy generation per unit length $[\mathrm{W} /(\mathrm{K} \mathrm{m})]$ \\
\hline$V_{C}$ & Fluid flow duty parameter \\
\hline & Volume of expansion $\left(\mathrm{m}^{3}\right)$ \\
\hline
\end{tabular}

fluid heat transfer without causing a damaging increase in the pumping power demanded by the forced-convection arrangement. The method combines from the start the most basic principles of thermodynamics, heat transfer, and fluid mechanics $[9,10]$.

For the heat exchanger, the entropy generation is described by Equation 2. Symbols used for the following set of equations are explained in Table 1.

$$
\dot{S}_{\text {gen }}^{\prime}=\frac{q^{\prime 2}}{\pi \kappa T^{2} N u}+\frac{32 m^{\prime 3} f}{\pi^{2} \rho^{2} T D^{5}} .
$$

The Nusselt number is a result taken from the field of heat transfer (Equation 3):

$$
N u=0.023 \operatorname{Re}_{\mathrm{D}}{ }^{0.8} \operatorname{Pr}^{0.4} .
$$

The friction factor is a result taken from fluid mechanics (Equation 4):

$$
f=0.046 \operatorname{Re}_{\mathrm{D}}{ }^{-0.2} \text {. }
$$

The entropy generation minimization is related to the optimal value for the pressure drop through a thermodynamic system and the maximization of the heat transfer, as reported in Equation 5:

$$
N_{\mathrm{S}}=\frac{\dot{S}_{\mathrm{gen}}^{\prime}}{\dot{S}_{\text {gen, } \min }^{\prime}}=0.856\left(\frac{R e_{\mathrm{D}}}{R e_{\mathrm{D}, \mathrm{opt}}}\right)^{-0.8}+0.144\left(\frac{R e_{\mathrm{D}}}{R e_{\mathrm{D}, \mathrm{opt}}}\right)^{4.8}
$$

The first term on the right-hand side is the contribution made by the heat transfer, while the second term is the contribution due to fluid friction. The 


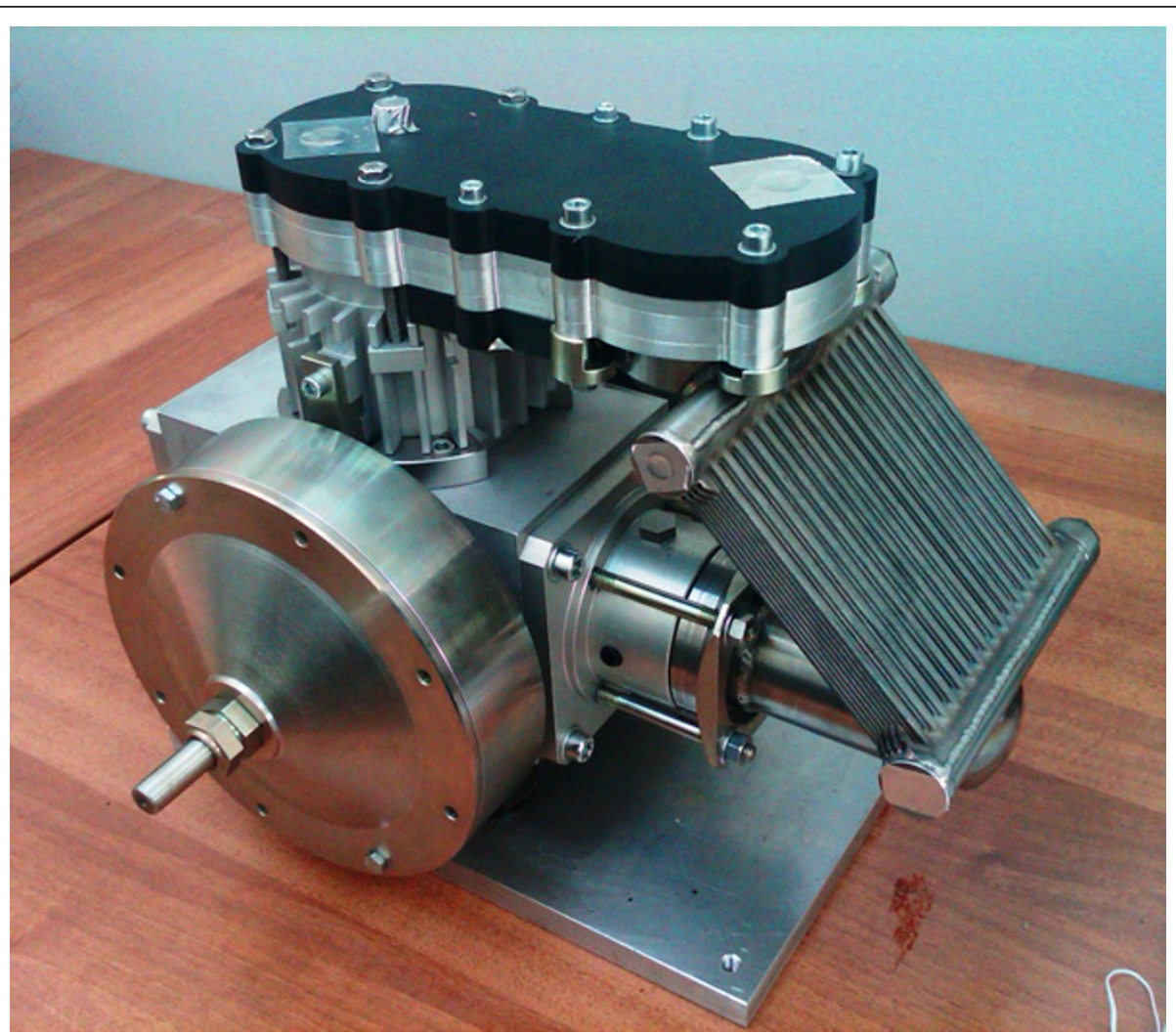

Figure 4 Prototype of the $\mathrm{mRT}-1 \mathrm{k}$ engine under manufacturing and realization in FBK
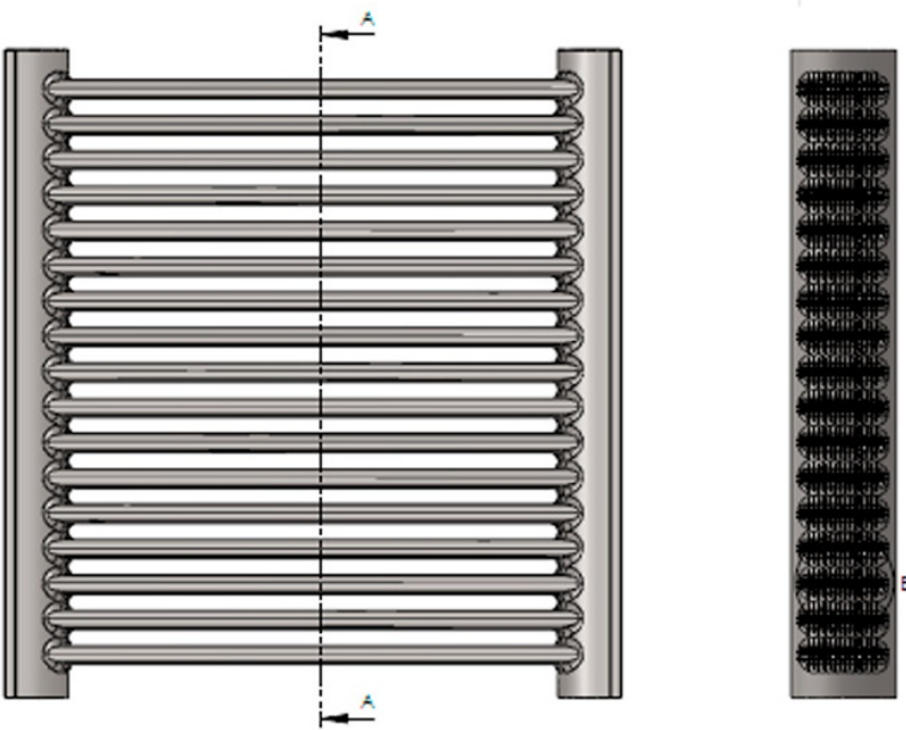

SEZIONE A.A
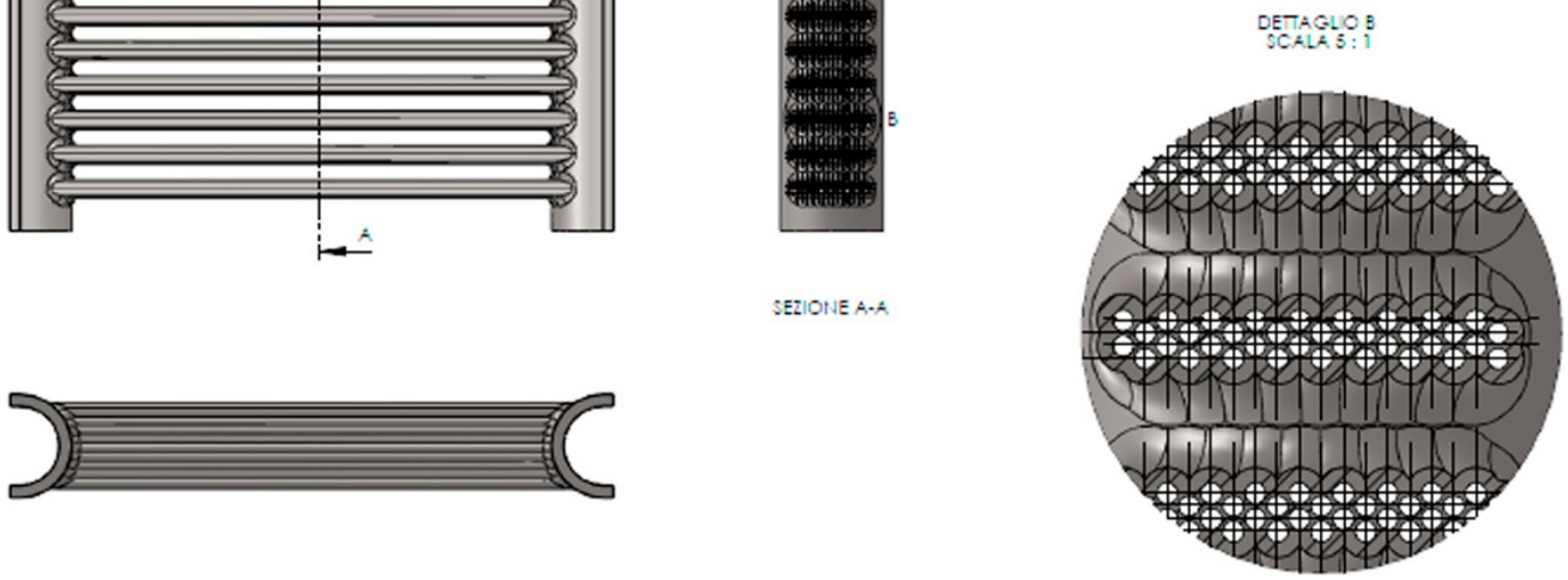

Figure 5 Model of the micro-heat exchanger realized for the Stirling engine 
following equation (Equation 6) can be derived for the optimal duct dimensioning of the internal flow. The optimal diameter is averaged over one complete cycle of the Stirling engine and is found in an iterative way.

$$
D_{\mathrm{opt}}=\frac{4 m^{\prime}}{\pi \mu\left(2.023 B_{\mathrm{o}}^{0.358} \operatorname{Pr}^{-0.071}\right)} .
$$

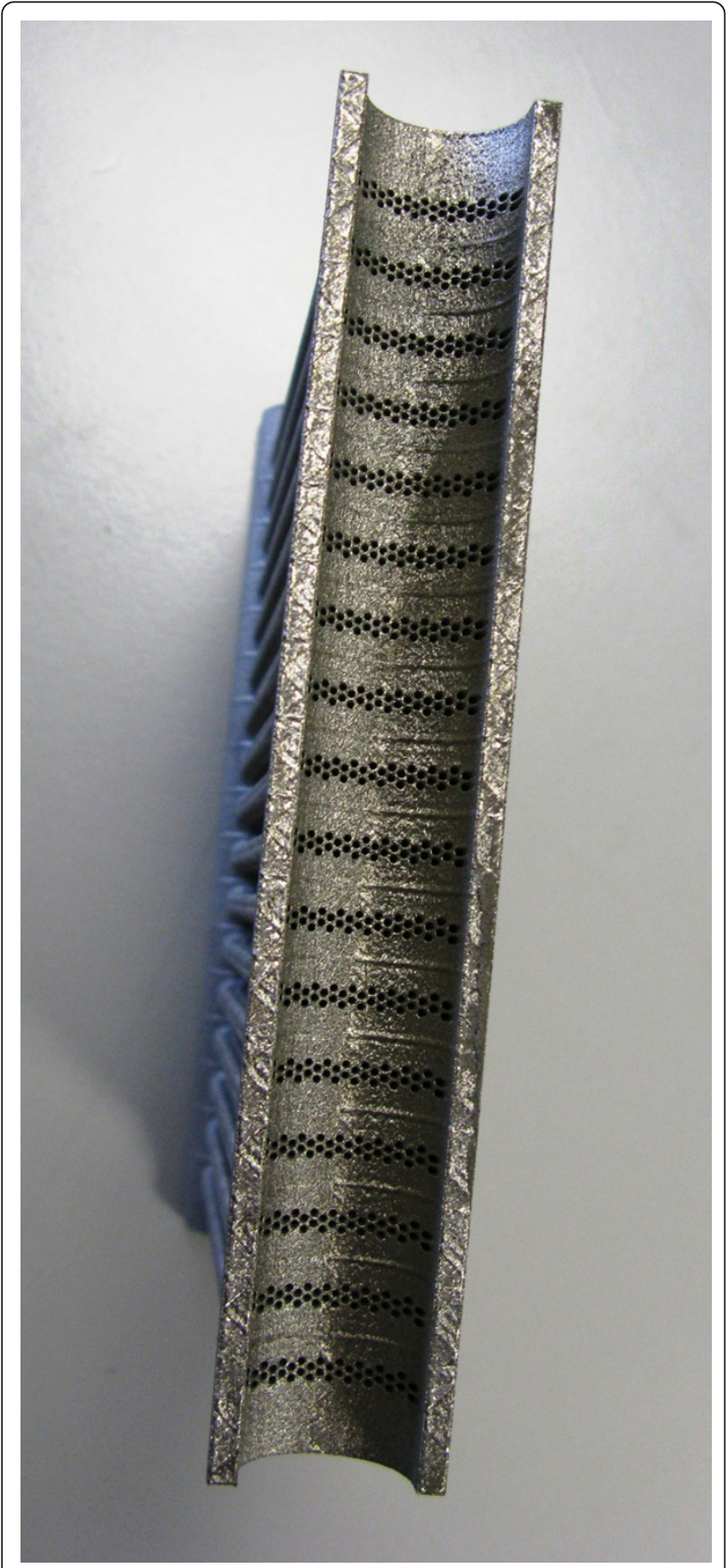

Figure 6 Top view of the heat exchanger from the manifold
For the proposed technology, an optimal diameter of 1.03 $\mathrm{mm}$ has been obtained for the internal forced flow. The modeled solution is based on a design which comprises 612 parallel fluid ducts of $1 \mathrm{~mm}$ in internal diameter and $600^{\circ} \mathrm{C}$ on the hot heat exchanger side. By using the same approach, the method could be extended to the external flow of the combustion products in order to obtain the whole optimization for the heat exchanger. The micro-heat exchanger has been realized through a SLM process from the micro-powder of AISI 316L stainless steel. The prototype is shown in Figures 6 and 7. The spatial resolution of the process can reach a value around $0.2 \mathrm{~mm}$.

\section{The pellet boiler}

The pellet boiler will be manufactured starting from an initial prototype to realize a final market technology. Figure 8 shows the first design for the boiler, which will have a dedicated burner (Figure 9) placed below the Stirling heat exchanger.

The pellet is inserted by an automatic spiral screw which can be controlled with respect to the heat input by changing its velocity. The primary air is injected at the burner level and controls part of the combustion process, the flame temperature, and power; it is able to provide the correct amount of combustive agent. Depending on process thermal requirements, the power can be ranged from 18 to $5 \mathrm{~kW}_{\text {th }}$, which is the minimum power required by the Stirling engine to generate $1 \mathrm{~kW}_{\mathrm{e}}$ at the output. While the peak power will be used to take the system at the working conditions, the steady state will be maintained through the minimum power to keep the engine running and generating electrical energy at a rated power output. In such way, the system will be cogenerating energy for a

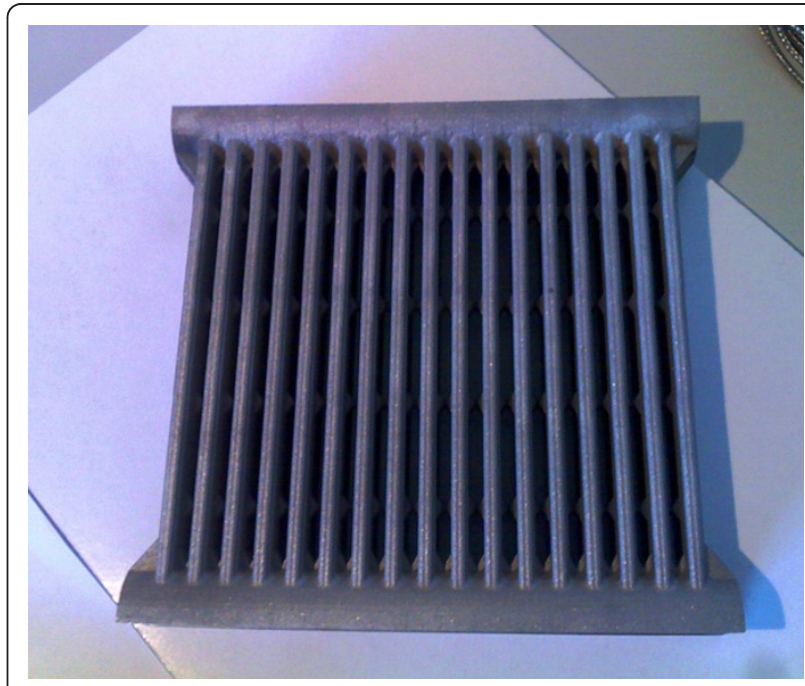

Figure 7 Side view of the heat exchanger 


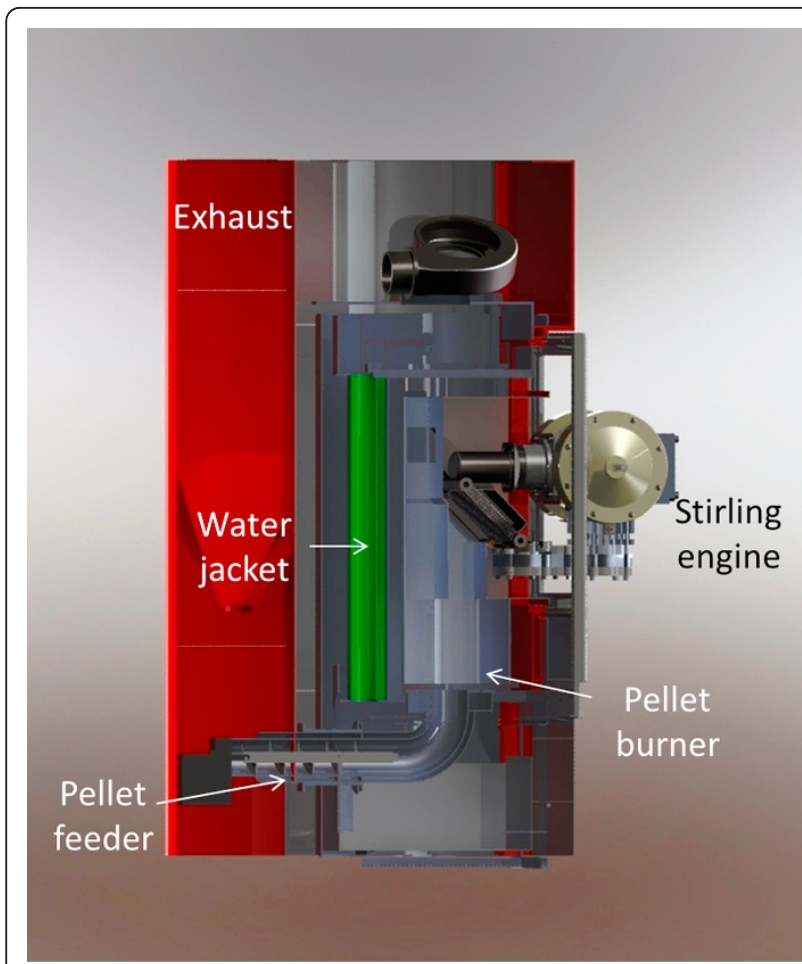

Figure 8 Pellet boiler rendering

larger amount of hours per year, increasing the economic benefits from the system. At the present time, it has not been possible to develop a full calorific value boiler due to potential corrosion effects at the exhaust of the system caused by particulate, sulfur, and other contaminants potentially at a dangerous concentration inside the biomass pellet.

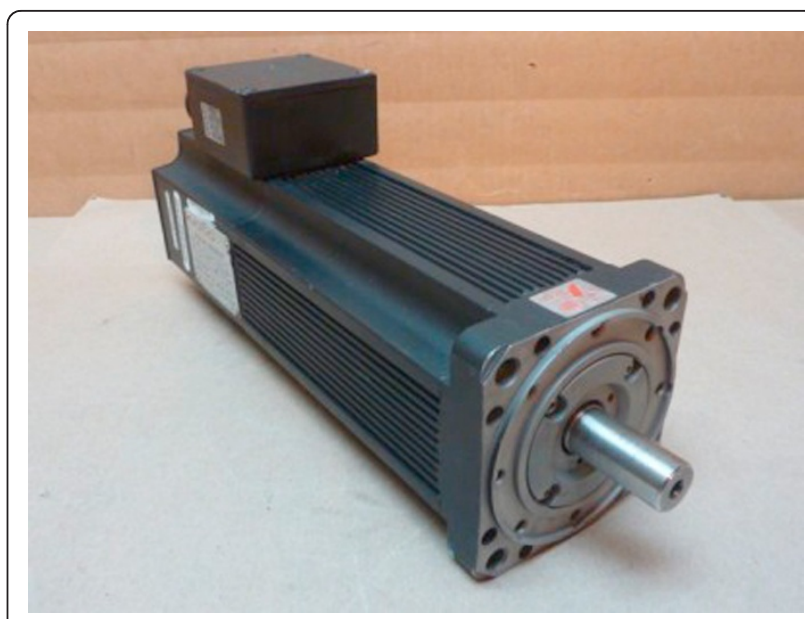

Figure 10 Moog's electrical generator.

\section{The electrical generator and the load management} system

The mRT-1k Stirling, to generate electrical power, is interfaced with an electrical generator and a control drive. The electric generator is a three-phase permanent magnet generator, customized by Moog Italiana, able to generate $1 \mathrm{~kW}$ el at a speed rate of $1,500 \mathrm{rpm}$ (see Figure 10).

The generated electrical power is controlled by monitoring the thermal energy generated by the pellet burner and transferred inside the Stirling engine. The drive control (see Figure 11) will brake the engine at an optimal speed at the maximum overall efficiency, coupling the rotational speed of the engine with the electrical power generated. At the same time, the generated

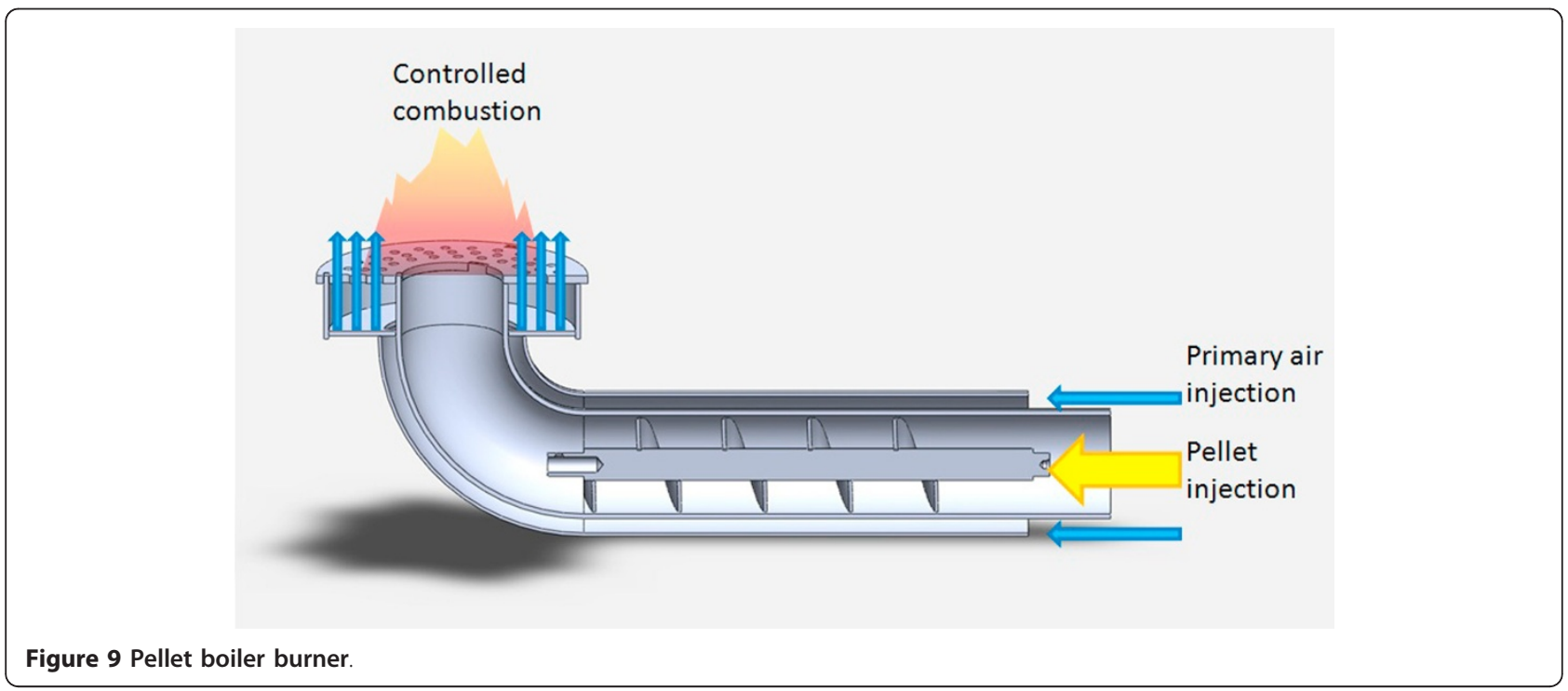




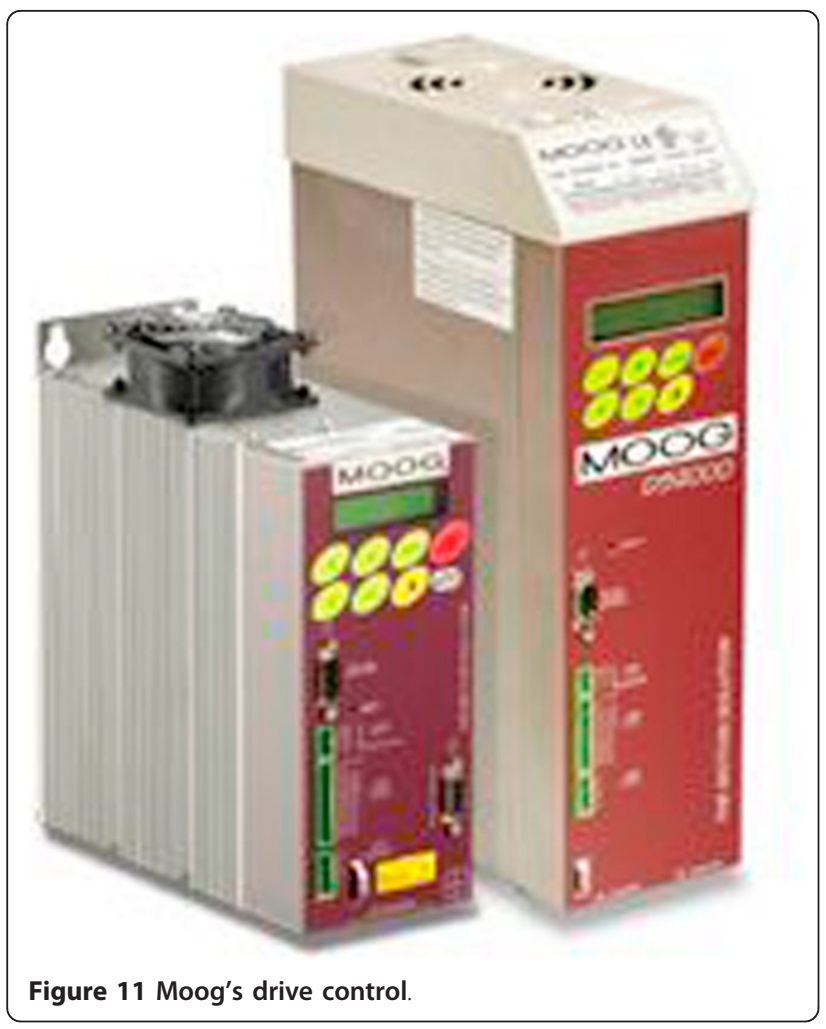

power requires stabilization to a fixed voltage level before the second stage of conversion to AC voltage. This must be pursued according the standards set by the energy management agency (i.e., $50 \mathrm{~Hz}$ of frequency value at a voltage of $230 \mathrm{ACV}$ and the admitted level of DC current components).
To perform the above described steps, a series of components has been selected, respectively a control drive provided by Moog Italiana (see properties in Figures 12, 13 and 14) and an inverter for wind power applications, suitable for a wide range of testing conditions.

The efficiency of these two electrical conversions are respectively $88-90 \%$ for the first stage between mechanical power and direct voltage and $90-95 \%$ for the second stage through the inverter, in the range of $1 \mathrm{~kW}_{\mathrm{e}}$. The efficiency can increase significantly at rising power over $2-3 \mathrm{~kW}_{\mathrm{e}}$. In a few months, the two conversions can be performed by a two-axis control drive under realization by Moog industries; this new drive control will integrate in a single unit the two previous mentioned systems and will be able to reach an overall efficiency of $92-95 \%$, integrating a sensorless generator control.

\section{Conclusions}

The presented technology is entering the testing process in laboratory-controlled conditions at a first stage of the $\mathrm{mRT}-1 \mathrm{k}$ tests and inside the boiler prototype in a second stage. The test bench has been realized in Fondazione Bruno Kessler [FBK] for both stages based on:

-Natural gas burner-controlled mass balance, through a mass flow controller applied to the gas duct, and energy balance, through the calculus of the energy content on the different stages, from the input gas mass flow to inside the engine and in the water external cooling circuit

-On the pellet boiler, mass and energy balance at the different stages, inside the burner, in the Stirling engine and in the water circuit

\section{Efficiency vs power}

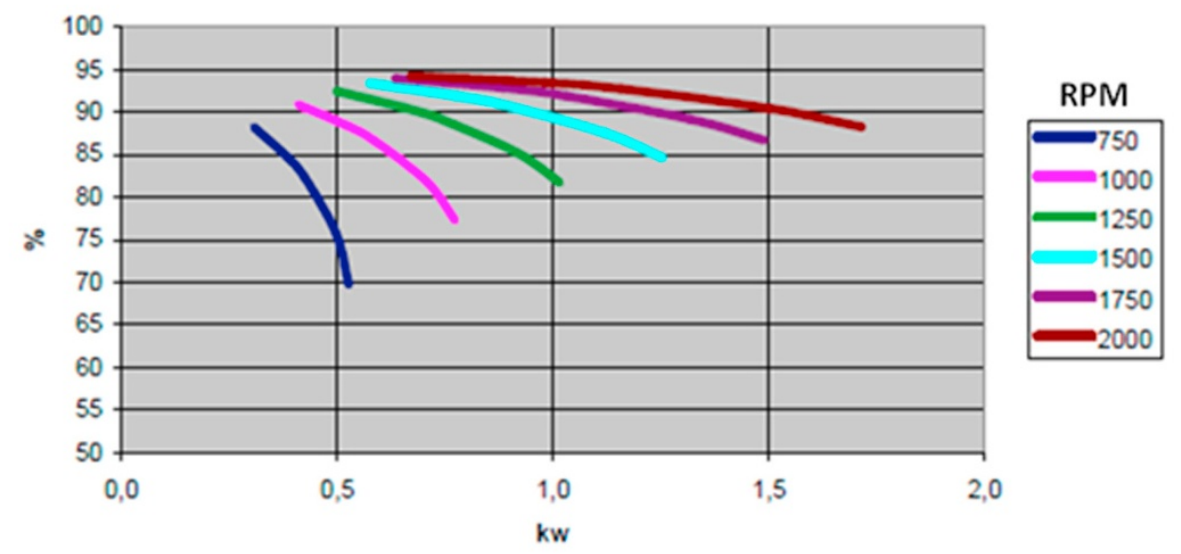

Figure 12 Generator efficiency vs. Power 


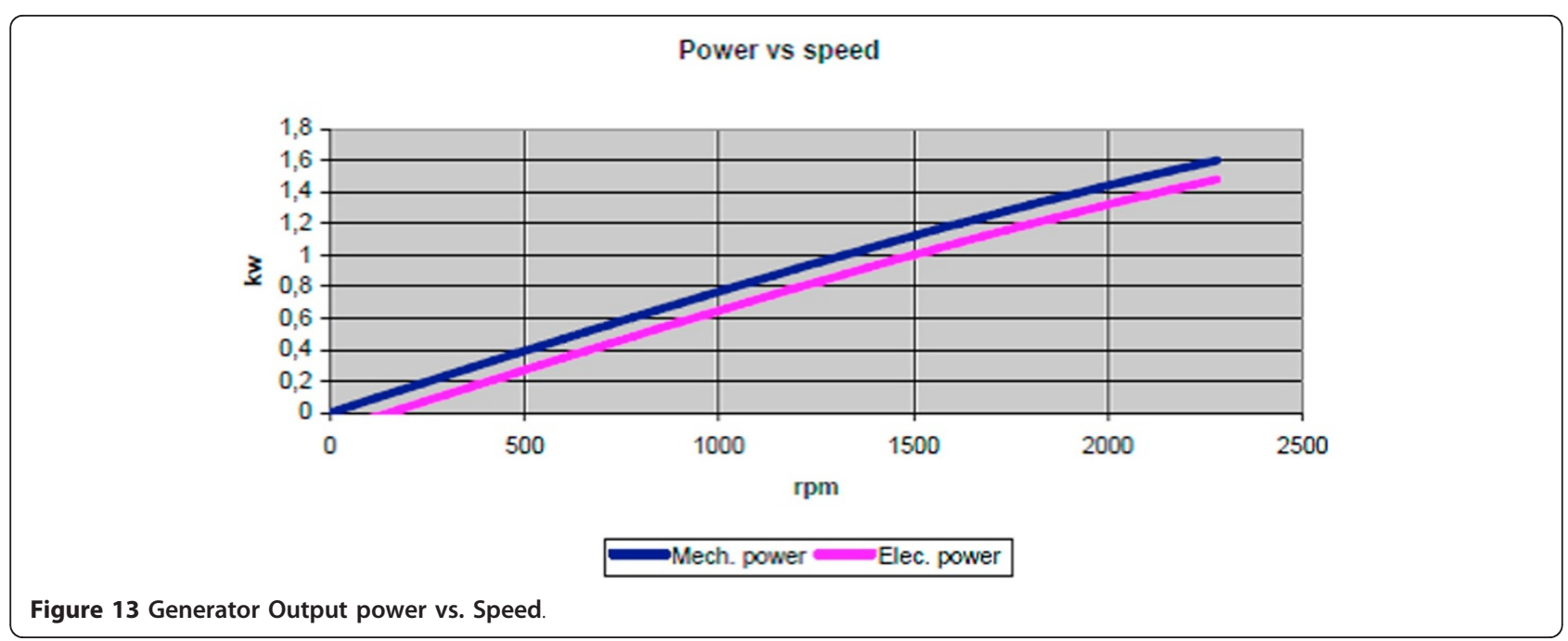

The technology will be tested with respect to performance and overall efficiency, noise level and reliability, long-term tests, and mean time before fault index. The full system will then be included in a series of planned projects inside the Province of Trento, such as the 'Tomorrow's Mountain Cottages,' a territorial program launched by the Province of Trento, and the 'FBK MIT Sustainable Connected Home', a project in cooperation between Fondazione Bruno Kessler and the Massachusetts Institute of Technology. A start-up activity has been planned for the industrialization and commercialization of the final technology. The impact at the local level can either be supported by the local

\begin{tabular}{|c|c|}
\hline Rated Speed (RPM) & 1500 \\
\hline Ambient Temp ${ }^{\circ} \mathrm{C}$ & 25 \\
\hline Rated Torque (Nm) & 7.1 \\
\hline $\begin{array}{l}\text { No load Voltage at rated } \\
\text { Power (Vrms) }\end{array}$ & 222.9 \\
\hline Rated Power (KW) & 1.00 \\
\hline Rated Current (Arms) & 2.9 \\
\hline $\begin{array}{l}\text { Efficency at rated power } \\
(\%)\end{array}$ & 89.2 \\
\hline
\end{tabular}

Energy Agency of the Province of Trento to smallscale biomass conversion plants and installations with respect to bigger cogeneration biomass power plants. A lot of the local activities are on the way to realize a whole chain of stakeholders involved at the local level [11].

\section{Acknowledgements}

The authors would like to extend some acknowledgements mainly to the Editor, to Dagmar Fiedler, to Michael Narodoslawsky, and all colleagues at TU Graz and eseia [European Sustainable Energy Innovation Alliance]. Special thanks also to the Autonomous Province of Trento and to the Energy Agency of the Province of Trento for supporting the demonstration of the technology in the BioDomUs project.

\section{Authors' contributions}

LC carried out main developments and scientific coordination on the technology design and realization. FA participated and performed all thermodynamic analysis and modelling. AB worked out the part on the mechanical design for the integration of the Stirling in the pellet boiler and has performed the development of the variable speed control system. ABo participated in the general definition of the technology and on the overall management, giving support to coordination. All authors read and approved the final manuscript.

\section{Competing interests}

The authors declare that they have no competing interests.

Received: 8 September 2011 Accepted: 21 November 2011 Published: 21 November 2011

\section{References}

1. Farrell J Distributed energy generation = big numbers.http://www.grist.org/ people/John \pm Farrell

2. Camisada D (2010) Building integrated concentrating photovoltaic: a review. Renew Sustain Energ Rev 15(1):603-611

3. DiGeSPo project Distributed generation from a small size concentrated solar power.http://www.digespo.eu/

4. Briguglio N, Ferraro M, Brunaccini G, Antonucci V (2011) Evaluation of a low temperature fuel cell system for residential CHP. Int J Hydr Energ 36(13):8023-8029

5. Palazzetti M Proposals to boost biomass for heat market in Europe.http:// www.aebiom.org/IMG/pdf/Palazetti.pdf 
6. Douard F Boosting bioenergy in Europe. Expobioenergia '06: Topics in Biomass Domestic Heating. First International Bioenergy Congress, Valladolid, October 2006

7. Strategic Assessment for European Biomass Energy Markets. Frost \& Sullivan. http://www.frost.com/prod/servlet/report-toc.pag?repid=M249-01-00-00-00

8. Organ AJ mRT-1k engine.http://web.me.com/allan.j.o/ Communicable_Insight/Welcome.htm

9. Bejan A (1996) Entropy generation minimization: the new thermodynamics of finite-size devices and finite-time processes. J Appl Phys 79(3):1191-1218

10. Durmayaz A, Sogut S, Sahin B, Yavuz H (2004) Optimization of thermal systems based on finite-time thermodynamics and thermoeconomics. Prog Energ Combust Sci 30:175-217

11. Giuliani F, Baldo M, Grisenti B La filiera foresta - legno - energia.http://www. legnotrentino.it/documenti/Pubblicazioni/2011/Maggio/ Report_Biomassa_def.pdf

doi:10.1186/2192-0567-1-5

Cite this article as: Crema et al:: Development of a pellet boiler with

Stirling engine for m-CHP domestic application. Energy, Sustainability and Society 2011 1:5.

\section{Submit your manuscript to a SpringerOpen ${ }^{\mathcal{O}}$ journal and benefit from:}

- Convenient online submission

- Rigorous peer review

- Immediate publication on acceptance

- Open access: articles freely available online

- High visibility within the field

- Retaining the copyright to your article

Submit your next manuscript at $\gg$ springeropen.com 